\title{
HISTÓRIAS ALÉM DO ESCRITO: \\ O CURRÍCULO PARA SURDOS E AS PRÁTICAS DIGITAIS NO COTIDIANO \\ ESCOLAR
}

HISTORIES BEYOND WRITING:

THE CURRICULUM FOR THE DEAF AND THE DIGITAL DAILY SCHOLAR PRACTICES

HISTORIAS MÁS ALLÁ DE LA ESCRITURA:

EL CURRÍCULO PARA SORDOS Y LAS PRÁCTICAS DIGITALES EN LA ESCUELA TODOS LOS

DÍAS

\author{
Jonata Souza de Lima ${ }^{1}$ \\ Érico Silva Muniz ${ }^{2}$
}

\begin{abstract}
RESUMO
Este artigo tem como objetivo discutir experiências de educação de surdos com o uso de tecnologia digital de informação e comunicação (TDIC) e da Língua Brasileira de Sinais (Libras) no ensino da disciplina de História. Este debate é contextualizado pela análise de intentos dispostos em propostas curriculares e como eles abordam as necessidades dos sujeitos surdos. Este trabalho tem por base pesquisa documental de leis, resoluções e currículos, além de pesquisa de campo com uso de entrevista estruturada com sujeitos formados em Licenciatura em História e que no seu fazer pedagógico utilizam a TDIC no trabalho com seus alunos surdos. As conclusões apontam para a necessidade de reformulação curricular com maior uso da TDIC, na visualidade e na valorização da Libras.
\end{abstract}

PALAVRAS-CHAVE: TDIC. Libras. Visualidade. Currículo. Surdez.

\section{ABSTRACT}

This article aims to discuss educational experiences for the deaf people with the use of digital information and communication technology (TDIC) and the Brazilian Sign Language (Libras) in the teaching of History. This debate is contextualized by the analysis of intentions arranged in curricular proposals and how they address the needs of deaf subjects. This work is based on documentary research about laws, resolutions and curriculum, and field research using structured interviews with subjects graduated in History and who in their pedagogical practice use the TDIC in their work with their deaf students. The conclusions point to the need for curricular reformulation with greater use of TDIC, in terms of visuality and appreciation of Libras.

KEYWORDS: TDIC. Pounds. Visuality. Curriculum. Deafness.

\section{RESUMEN}

Este artículo tiene como objetivo discutir las experiencias de educación para sordos con el uso de la tecnología de la información y la comunicación digital (TDIC) y la Lengua de Signos Brasileña (Libras) en la enseñanza de la

Submetido em: 30/05/2020- Aceito em: 07/08/2020 - Publicado em: 18/08/2020

\footnotetext{
${ }^{1}$ Universidade Federal do Pará.

${ }^{2}$ Universidade Federal do Pará.
} 
Historia. Este debate se contextualiza mediante el análisis de intenciones ordenadas en propuestas curriculares y cómo abordan las necesidades de los sujetos sordos. Este trabajo se basa en la investigación documental de leyes, resoluciones y planes de estudio, además de la investigación de campo mediante entrevistas estructuradas con sujetos egresados de la Licenciatura en Historia y que en su práctica pedagógica utilizan el TDIC en su trabajo con sus alumnos sordos. Las conclusiones apuntan a la necesidad de una reformulación curricular con mayor uso de TDIC, en términos de visualidad y apreciación de Libras.

PALABRAS CLAVE: TDIC. Libras. Visualidade. Plan de estúdios. Sordera.

\section{INTRODUÇÃO}

Este artigo tem como objetivo discutir o uso da Tecnologia Digital de Informação e Comunicação (TDIC) e da Língua Brasileira de Sinais (Libras) como primeira língua na educação de surdos durante o processo de ensino-aprendizagem das disciplinas História e Estudos Amazônicos. Nessa perspectiva, consideramos também a utilização do português, na modalidade escrita, como segunda língua. Partimos da premissa que no tempo presente, apesar da inclusão de um maior número de alunos surdos no espaço físico escolar, garantido por conta da aceitação e legitimação da Libras, através da Lei n. 10.436, de 24 de abril de 2002 e do Decreto n. 5.626, de 22 de dezembro de 2005, a mesma não tem sido suficiente para dar origem a práticas pedagógicas efetivamente inclusivas. Este direito conquistado ainda não foi estendido, portanto, ao uso do espaço digital através da TDIC, pois como discutiremos, urge a necessidade de práticas pautadas em uma Pedagogia Visual que tenha o potencial de abarcar as necessidades curriculares deste alunado surdo das escolas da educação básica no ciberespaço.

Como salienta Corrêa e Cruz (2019, p. 57) é recente o quantitativo expressivo de surdos que tem "atingindo níveis escolares mais elevados" e essa permanência maior dos surdos na escola está sendo estruturada em concomitância com novos debates sobre o uso da TDIC. Dessa forma, há uma grande possibilidade de entrelaçar o uso das novas tecnologias ao processo pedagógico surdo. Contudo, isso deve estar na formação e no fazer pedagógico do professor de História que tem o contato educacional direto com este estudante.

A TDIC permite múltiplas abordagens teórico-metodológicas que podem maximizar as experiências pedagógicas, por isso realizamos uma discussão da metodologia de ensino das disciplinas de História, disciplina estruturada no currículo brasileiro e reformulada na Base Nacional Comum Curricular (BNCC, 2017). Nossa pesquisa de campo abarcou especialmente o contexto da Amazônia paraense, onde além da disciplina História, muitos conteúdos sobre as sociedades que viveram em outros tempos são abordados na disciplina de Estudos Amazônicos, segundo o currículo das escolas paraenses, respaldado pelo Documento Curricular do Estado do Pará (DCEP, 2019). Ambas disciplinas, História e Estudos Amazônicos, estão estruturadas nos componentes curriculares da área de Ciências Humanas. Ainda em um debate interdisciplinar, é necessário considerar também a área de conhecimento das Linguagens que formalmente abarca o componente curricular de Língua Portuguesa e a Libras, esta última que 
ainda está em vias de ser ofertada dentro da educação básica como disciplina eletiva , mas já compõe o currículo da educação superior em Licenciaturas (LINS, 2012).

De antemão é importante debater uma compressão do senso comum de que a presença do tradutor intérprete de Libras (TILS) e o uso da Libras já se configura como o alcance da inclusão de surdos no cotidiano escolar (DAMÀZIO, 2007). No entanto, há mais nuances no processo de inclusão destes alunos que passam, por exemplo, pela necessidade do uso da TDIC. Através de pesquisa com sujeitos com formação e atuação na área de História que dominam tanto a TDIC quanto a Libras, visamos coletar experiências em temas pertinentes ao exercício da docência em História envolvendo alunos surdos, discutindo pontos fundamentais sobre a educação de surdos. Utilizaremos as falas dos entrevistados organizadas em aspas duplas por consideramos esses sujeitos autores de importantes reflexões pedagógicas.

Para a coleta de dados entre esses profissionais, foi montado um questionário estruturado padrão do Google Formulários, em formato bilíngue, com tradução integral de todos os itens: perguntas, apresentação e termo de consentimento. As respostas foram oportunizadas tanto em Língua Portuguesa quanto em Libras. Tal proposição foi levantada para que pudéssemos contemplar a participação de surdos. Infelizmente, como o recorte privilegiava profissionais formados em História, não foi possível contemplar a narrativa de surdos, já que estes não se concentram em um quantitativo expressivo na área de História, sendo mais frequente que surdos invistam em áreas como Pedagogia, Pedagogia Bilíngue e Letras/Libras. Com essa realidade, estamos cientes que muitas pesquisas na área da surdez focam nas "experiências docentes, a partir de uma ótica ouvinte" (LINS, 2012, p. 13).

Na etapa da pesquisa realizada à distância, com os formulários, os sujeitos pesquisados são oriundos de várias localidades do Brasil e relacionam-se muito bem com a telemática, o que possibilitou o contato com eles para obtenção de outras respostas e diálogos mais aprofundados usando as mídias sociais tradicionais.

Quadro 01. Grupo de sujeitos pesquisados: Especialistas da área.

\begin{tabular}{|c|c|c|}
\hline Sujeito & Formação & Atuação \\
\hline Entrevistado A & $\begin{array}{c}\text { Graduado em História e } \\
\text { Doutorando em História. }\end{array}$ & $\begin{array}{c}\text { Pesquisas na área da surdez e ensino de História } \\
\text { para surdos, formação da graduação e pós- } \\
\text { graduação na área de História. Possui fluência } \\
\text { em Libras, atua como professor de AEE. }\end{array}$ \\
\hline Entrevistado B & $\begin{array}{c}\text { Graduado em História e } \\
\text { Especialista em Libras e TDIC. }\end{array}$ & $\begin{array}{c}\text { Ensino de História para surdos presencial e em } \\
\text { EaD. Atua como intérprete e professora da } \\
\text { educação básica. }\end{array}$ \\
\hline Entrevistado C & $\begin{array}{c}\text { Graduado em História, } \\
\text { Doutor e possui Cursos de Libras. }\end{array}$ & $\begin{array}{c}\text { Pesquisas na área da surdez e ensino de História } \\
\text { para surdos. Possui fluência em Libras. }\end{array}$ \\
\hline
\end{tabular}




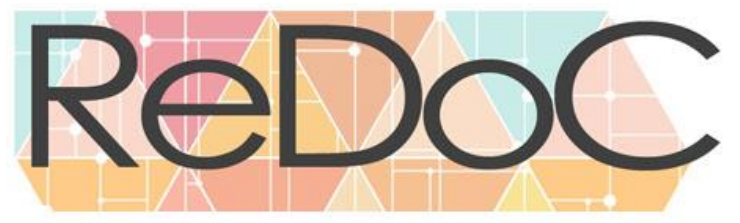

Revista Docência e Cibercultura

\begin{tabular}{|c|c|c|}
\hline Entrevistado D & $\begin{array}{c}\text { Graduada em História e } \\
\text { Especialista em Libras e AEE. }\end{array}$ & $\begin{array}{c}\text { Ministra a disciplina de Libras e atua na } \\
\text { comunidade surda da região pesquisada. }\end{array}$ \\
\hline Entrevistado E & $\begin{array}{c}\text { Graduado em História e Especialista } \\
\text { em Libras e TDIC. }\end{array}$ & $\begin{array}{c}\text { Intérprete de Libras na educação básica e realiza } \\
\text { trabalhos artísticos com mídias sociais. }\end{array}$ \\
\hline Entrevistado F & $\begin{array}{c}\text { Graduado em História e Especialista } \\
\text { em Libras e AEE. }\end{array}$ & $\begin{array}{c}\text { Pesquisas na área da surdez, docência em Libras } \\
\text { e intérprete de Libras. }\end{array}$ \\
\hline
\end{tabular}

Fonte: Elaborado pelos autores do trabalho.

Nas entrevistas, buscamos explorar temas específicos sobre o universo da educação de surdos e as questões específicas da área de História, tais como: o conhecimento de Libras; o conhecimento de especificidades da educação de surdos, a relevância de métodos tecnológicos (uso de videoaulas, sites como TV INES e YouTube), o conhecimento sobre canais alternativos bilíngues, a ocorrência do sentimento de inclusão, os impactos das novas tecnologias na educação de surdos, a importância da disciplina História, o domínio dos conteúdos de sujeitos e fatos regionais (em Estudos Amazônicos), e, os termos da Base Nacional Comum Curricular (BNCC).

\section{A VISÃO DE ESPECIALISTAS NA EDUCAÇÃO DE SURDOS}

A disciplina de História é vista tradicionalmente como aquela que se alimenta das fontes escritas oriundas de documentos textuais, mas na atualidade, com as várias reconfigurações das linguagens e saberes humanos, estudos revelam que as novas formas de apreensão do conhecimento ocorrem também pela oralidade, pelos sons e pela visualidade. Dessa maneira, podemos colocar a escrita como apenas uma das muitas formas, de se conhecer e lecionar os conteúdos da área de Humanidades (BITTENCOURT, 2008). No entanto, a estrutura curricular tende a privilegiar a oralidade e a escrita em História e em Estudos Amazônicos bem como em outras disciplinas gerando assim, "práticas pedagógicas majoritariamente como ouvintizadas" (WITKOSKI, 2012).

O professor de História e de Estudos Amazônicos, ao se deparar com alunos surdos, tem o desafio de questionar a própria lógica do sistema educacional pautado quase que exclusivamente na leitura, na escrita e na oralidade. Portanto, o docente necessita estar aberto a repensar suas práticas pedagógicas de maneira que oportunizem a Libras e uma Pedagogia Visual. Pesquisas recentes levantam esta proposição, evidenciando insatisfações quanto à baixa usabilidade da Libras na sala de aula e a persistência de uma visão oral, ou seja, continuamos "sob a égide da preocupação pedagógica com o domínio do código escrito, em seu aspecto gramático-formal, ainda considerando a predominância da linguagem oral nesse processo, ao invés das línguas de sinais" (LINS, 2012, p. 76).

A Libras é uma língua na modalidade vísuo-espacial, é este "o canal perceptual adequado à aquisição e à utilização da linguagem pelas pessoas surdas", inclusive para a sua percepção de 
mundo. Por sua vez, a Língua Portuguesa, "oral-auditiva”, geralmente é a segunda língua de instrução, mas que interage artificialmente com a percepção de mundo da pessoa surda (SALLES, 2004). A língua vísuo-espacial dos surdos tem implicações cruciais para seu desenvolvimento cognitivo, é por ela que ocorrem afirmação social e realização pessoal. Mas, essa relação, embora reconhecida pelo Ministério da Educação (MEC), acaba não sendo materializada na construção das bases curriculares em âmbito federal e nos estados. Até hoje há muitas questões a serem sanadas quanto ao uso e difusão da Libras na educação básica. Por exemplo, na LDB/96 há uma referência direta ao ensino de outras línguas, como língua inglesa (art. 26, § 5), língua espanhola (art. 35-A, § $4^{\circ}$ ) e línguas indígenas (Art. 78), porém nenhuma alusão ainda era feita à Libras.

O conhecimento do conteúdo da BNCC foi uma das questões levantadas na pesquisa de campo, mas os docentes entrevistados, de forma unânime, apresentaram pouco conhecimento sobre o documento, o que parece ser um fenômeno tanto na educação básica quanto superior. Os entrevistados não conhecem o texto integral da BNCC, tomando conhecimento dos seus debates através de opiniões de terceiros e de leituras de outros referenciais. Skliar (2011, p. 41) aponta um fenômeno de estruturação do currículo que na, maior parte das vezes, é organizado pelo já citado viés ouvintista, isso pode ser maximizado se a comunidade surda não tomar posse dos debates sobre o currículo pelas fontes primárias.

Nesse viés, Witkoski (2012, p. 97) debate o currículo ouvintista usado na escola indagando que há "ouvintização do currículo escolar marcado pela ausência absoluta do sujeito surdo e suas referências culturais". Esses elementos de ouvintização marcam a própria BNCC, fonte primária do currículo escolar na atualidade, uma vez que este documento pretende a generalização curricular, não se atentando às especificidades dos surdos e de outros grupos de minorias, normalmente, o público-alvo do atendimento educacional especializado (AEE).

No caso do Pará, há na esfera estadual a possibilidade de adaptação dessa BNCC para uma estrutura que contemple as demandas daquele ente federativo. Isso ocorre pelo DCEP (2019), que na prática apenas compila as questões gerais da BNCC. Retomando Witkoski (2012), cabe, portanto, à instituição escolar subverter essa lógica ouvintista organizada pelos entes federal e estadual.

Quando questionados se conheciam a BNCC, sua visão e importância sobre ela, ou ainda outros documentos que possam nortear seus processos pedagógicos, os entrevistados revelam suas concepções sobre a importância da legislação. O Entrevistado A disse que precisava se "aprofundar na BNCC", mas que tem "atuado muito com o programa do Enem (Exame Nacional do Ensino Médio)". A importância do Enem também foi levantada pelo Entrevistado $\mathrm{D}$, o que nos remete ao muito denunciado processo de organização curricular pautado nas avaliações externas. Isso impede uma proposição de "procurar um currículo em que os surdos pensem, repensem conosco formas e caminhos formativos trazendo como premissa o pensar em sua singularidade" (LINS, 2012, p. 62).

Todos os entrevistados concordam que a ideia de uma base nacional é necessária para balizar 
a educação brasileira e há ressalvas, como a do Entrevistado $\mathrm{C}$, ao dizer que neste documento existem "coisas que não dialogam com as particularidades linguísticas, muito menos com elementos que denotam o processo de valorização às singularidades ao tocante à diversidade do país". São essas particularidades linguísticas que devem ser discutidas dentro da escola para que essa instituição possa organizar um currículo voltado para o alunado surdo. Essa afirmação ganha contornos ainda mais fortes se pensarmos nas peculiaridades da Amazônia brasileira, historicamente sujeita a aplicar currículos e materiais didáticos pensando majoritariamente no sul e sudeste do país. Mesmo porque a questão linguística a e visualidade são dois elementos primordiais para a formação cultural dos surdos (STROBEL, 2009).

Na estrutura da BNCC (2017) e no DCEP (2019), em todas as disciplinas, permanece a escrita, a leitura e a oralidade como a base da percepção do conhecimento. Ou seja, mantém-se uma concepção canônica no pensamento docente, em que a tríade é a base para a educação. Isso se revela como uma desvantagem para o aluno surdo, já que ele está sendo educado por indivíduos que ainda não concebem, por exemplo, o canal visual como a sua principal forma de aprendizado.

A especificidade educacional do surdo no DCEP (2019) é concebida de uma forma absolutamente descontextualizada na área de "Conhecimento das Ciências da Natureza" no Componente Curricular de "Ciências" destinado aos alunos do $1^{\circ}, 2^{\circ}$ e $3^{\circ}$ ano do ensino fundamental dentro do eixo de "valores à vida social", no subeixo de "dignidade humana, corpo e saúde", trazendo a Libras com objetivo de aprendizagem a ser compreendida como forma diversificada de Linguagem. Essa forma de linguagem é apresentada como aquele destinada às pessoas portadoras de deficiência para a diminuição das barreiras comunicacionais. Como habilidade, espera-se que o alunado neste ano escolar consiga identificar a Libras como forma diferenciada de linguagem que favorece à comunicação e à socialização dos portadores de deficiência no ambiente escolar e social (DCEP, 2019, p. 286). Na visão socioantropológica, os surdos não se identificam ou se reconhecem, primordialmente, pela "deficiência", mas sim pelas experiências visual e linguísticas que se expressam na forma como se comunicam com uso da língua de sinais.

Essa única alusão à Libras dentro do DCEP (2019), além de insuficiente para conquistar a habilidade tão almejada pela comunidade surda, que é o rompimento da barreira comunicacional, está totalmente descontextualizada com a teoria vigente e com os intentos dos sujeitos surdos. A Libras é apresentada como "linguagem", embora toda a teoria já aceite essa forma de comunicação como "língua" e o surdo é definido exclusivamente como "portador de deficiência", rótulo condenado pela comunidade surda que vê sua situação como uma identidade, uma forma de estado cultural (sujeito) e não clínico (portador).

Para além disso, a estrutura curricular da BNCC (2017) lança a Libras em uma espécie de "lista de desejos". O DCEP (2019), por sua vez, tenta materializar este intento lançando-a como linguagem destinada a portadores de deficiência. Essa situação gera o que Witkoski (2012 p. 70) problematiza como "o currículo ouvintizado e infantilizado, além de não promover a 
interação com a cultura ouvinte, perpetua a exclusão da cultura surda". A construção de um currículo seguindo apenas essas premissas das estruturas federal e estadual, gera fracasso escolar e crescimento de surdos iletrados funcionais, o que pode ocorrer até mesmo em escolas bilíngues e inclusivas.

Ou seja, uma questão primordial para o desenvolvimento de uma metodologia bilíngue é a valorização de uma abordagem que insira a visualidade na educação de surdos, uma Pedagogia Visual. Para Skliar (2011, p. 44), deve-se pensar na expressão do ato comum da comunicação, "com o máximo aproveitamento dos recursos de imagem no lugar de falar e escrever, comum nas escolas de pessoas ouvintes, mas tão inadequado para as escolas que trabalham com pessoas surdas". Apenas assim os surdos superariam as dificuldades que encontram na aquisição dos conteúdos escolares.

Há vários outros trechos em que a BNCC (2017) traz a questão sensorial auditiva, a oralidade e a escrita como primeiro plano quer seja na educação infantil, ensino fundamental ou ensino médio. No ensino de História temos, por exemplo, alusão a "identificar as transformações ocorridas nos meios de comunicação" dando ênfase à "cultura oral" (BRASIL, 2017, p. 413) e distinguir "alguns significados presentes na cultura material e na tradição oral dessas sociedades" (BRASIL, 2017, p. 421). O DCEP (2019) compila essas questões na disciplina de História e as reestrutura na disciplina de Estudos Amazônicos. Com isso, podemos dizer que há nos documentos um viés oralista, pois os mesmos evidenciam a Língua Portuguesa escrita como primeira base, ignorando assim os intentos de uma educação bilíngue.

Quando questionados sobre os recursos metodológicos, observamos entre os educadores entrevistados uma ligeira confusão sobre o que seria uma metodologia de ensino. Por exemplo, o Entrevistado A coloca a Libras com a mesma função de "imagens, vídeos e textos menores". Não são feitas, portanto, a reflexão e a distinção do que seria o recurso e o que seria a metodologia "em si". O sujeito Entrevistado B reflete nesta questão sobre o uso da "Pedagogia Visual" a necessidade de se conhecer as especificidades da "cultura surda" para integrar uma abordagem de ensino e nos pressupostos da metodologia bilíngue. Da mesma forma os Entrevistados C e D pautam suas respostas nos "recursos imagéticos" que mais à frente são apresentados como os mencionados recursos visuais que valorizam o canal vísuoespacial do surdo em detrimento da oralidade que ainda permeia o espaço escolar e pode ser um problema para o aprendizado de alunos surdos.

Lins (2012) destaca que a percepção do surdo como sujeito visual e a intervenção imagética são as bases para reverter fracassos escolares na formação dos surdos. Nas palavras da autora “os alunos surdos tornam-se 'atrasados', não porque não ouve ou porque usa a língua de sinais, mas porque a escola e as políticas educacionais não levam em conta a necessidade de um ensino alicerçado na percepção visual" (LINS, 2012, p. 77). Essa questão foi bem frisada pelo Entrevistado E que demonstra o quanto acessível está o uso da imagem através de "imagens do livro, imagens da internet ou usando o próprio celular". O Entrevistado F indaga que "a fluência na Libras é muito importante, além de imagens e textos objetivos", em suas falas, este 
entrevistado discute que há necessidade de um uso sincrônico de imagens e Libras.

Enquanto Lins (2012) discute "fracasso escolar", temos na obra de Witkoski (2012, p.15) um debate sobre os "iletrados funcionais" que o próprio sistema escolar produz ao insistir com práticas bimodais. A prática bimodal, conforme essas autoras, está associada à permissividade da Libras, mas enquanto possibilidade legalmente conquistada, essa língua, embora legitimada pela comunidade lusófona, ainda tem de submeter-se ou subordina-se à Língua Portuguesa. Nesse contexto, desaparece o bilinguismo sugerido na legislação e nas teorias educacionais para surdos e surge a diglossia no sistema escolar. Há formas de subverter essa lógica ainda que parcialmente mesmo com a baixa contratação e disponibilização de recursos humanos especializados, através da TDIC, pois há, por exemplo vasto conteúdo imagético já produzido pela comunidade surda nas redes sociais.

Witkoski (2012 p. 62) discute as formas de abordagens que têm papel determinante na metodologia bilíngue, mas quase tudo depende do conhecimento prático do professor. Não basta utilizar as tecnologias digitais como filmes, recursos visuais potencialmente ricos se $\mathrm{o}$ próprio professor não tiver domínio teórico-metodológico sobre o tema. A depender da maneira como será utilizado, necessitando da "definição de objetivos claros e uma forma de avaliação predefinida", para validar ou não sua significância e eficiência no ensino e na aprendizagem, do contrário, aquela atividade só terá como fim, consumir tempo e carga horária do aluno surdo. Apesar dessas questões parecerem óbvias, há uma má aplicação dos recursos visuais mesmo aqueles amparados na TDIC mais autônoma e autoexplicativa, gerando efeitos alienantes e baixa eficácia no processo de ensino e aprendizagem.

Pensando nessas questões, foi discutido nas entrevistas a visão dos especialistas sobre o papel da telemática na educação de surdos. Os que possuem maior intimidade com a cultura surda demonstram aptidão no uso de tecnologias, como videoaulas e aplicativos de Libras para o ensino de História. Para o Entrevistado C, as tecnologias são consideradas "como o divisor de águas dentro do processo de inclusão no sistema de ensino", pois atingem tanto a sociabilidade, o aprendizado e o mercado de trabalho, sendo assim, o professor regular de História que inicia sua vivência pedagógica com alunos surdos, não deve se furtar em tomar posse dessas novas proposições baseadas na telemática. O Entrevistado $\mathrm{F}$ vai ao encontro da visão do Entrevistado $\mathrm{C}$, suas falas salientam que a TDIC corrobora maciçamente com a percepção de conhecimentos pelo aluno surdo.

Compreender a empregabilidade da TDIC na educação de surdos é de caráter interdisciplinar, de modo que várias pesquisas apresentam os ambientes virtuais de ensino e aprendizagem em plataformas digitais acessíveis em Libras como forma de ampliar o aprendizado e percepção dos surdos. Correa e Cruz (2019, p. 39) indagam que os docentes mais inovadores "utilizam tecnologias de informação e comunicação que podem mediar facilmente a interpretação a distância da língua de sinais, contribuindo para a formação, o acesso à informação e a difusão da cultura para surdos". 
Todos os entrevistados fazem uso em algum nível de plataformas tecnológicas em suas práticas pedagógicas, já que como salienta o Entrevistado A, elas possuem material que são construídos "a partir de imagens e não da fala", e por isso, atingem melhor as especificidades dos surdos. O Entrevistado B ressalta que "os sinalários dão suporte para que consigamos conceitos em Libras tornando a aula mais significativa". Ainda na visão desta entrevistada, as produções surdas vinculadas a TDIC refletem a própria visão dessa comunidade sobre suas percepções de mundo. Já o Entrevistado C considera os sites como "instrumentos relevantes, pois possibilitam aos alunos ampliarem seu vocabulário para uma melhor construção de diálogos em sua rotina, seja escolar ou fora dela".

Conforme Lins aponta (2012, p. 35), isso pode ser um fenômeno comum, uma vez que há profissionais que agem motivados "pela expansão da internet e das tecnologias", o que faz com "grande número de pessoas busque informações neste espaço, utilizando-o como meio de ensino e aprendizagem". A própria autora, na descrição das experiências docentes ligadas à educação de surdos, demonstra haver uso do ambiente virtual e da telemática entre as propostas de intervenção mais inovadoras e de sucesso. O Entrevistado D salienta ser importante que o professor de História busque formas de focar em trabalhos produzidos pela comunidade surda, já que na atualidade estamos em outro contexto, em que a prova do Enem é produzida em Libras, porém, com referências de língua de sinais que, muitas das vezes, são melhores assimiladas por surdos do sul e sudeste do país. Logo, quem se apossa dos conhecimentos externos à sua cidade acaba se capacitando com os sinais-termos a serem mais tarde na avaliação do ensino médio. Do contrário, o aluno surdo irá para este tipo de avaliação ainda com muita influência de uma variação linguística tão somente regional.

Corrêa e Cruz (2019, p. 35) discute essa questão salientando que "muita das vezes torna-se difícil evitar o regionalismo porque nem todos os sinais são dicionarizados ou iguais em todos os Estados". A TDIC tem o potencial para romper essas barreiras regionais, impactando mais os surdos oriundos dos interiores e trazendo com mais relevância os sinais de prestígio acadêmico. Ou seja, quanto mais rápido o surdo toma posse de um vocábulo mais nacionalizado da Libras, menos prejuízo este pode ter em uma eventual videoprova em Libras. Assim, a aplicação da TDIC pode representar também recurso de rompimento de barreiras, oferecendo ao estudante surdo a possibilidade de aquisição de uma "Libras nacionalizada" que o favorecerá no aperfeiçoamento linguístico e o capacitará para avaliações externas e outras experiências com comunidades surdas por todo Brasil.

Ainda com relação ao uso de videoaulas no cotidiano escolar, o Entrevistado E usa-as principalmente quando o tema é muito complexo ou faltam-lhe sinais para traduzir aquela temática. Os outros entrevistados demonstram opiniões quase idênticas, somente o Entrevistado $\mathrm{D}$ faz advertência ao uso deste recurso de forma mais cotidiana. Sobre os canais do YouTube, o Entrevistado D salienta como problema que os mesmos devem ser indicados com restrições, já que essa plataforma tem de ser "filtrada", porque assim como há conhecimentos que são científicos mais aprimorados, há também o que chama de "canais mais amadores". 
Para além do uso dos recursos tecnológicos, outras abordagens são bem-vindas, principalmente a que evidencia o conhecimento em lócus. Dessa forma, como evidenciam os Entrevistados A e B, visitar os "espaços de memória", como "visitas a museus e visitas a lugares importantes para a história local" são indispensáveis para o aprendizado e formação da consciência histórica por parte de um aluno surdo. Bittencourt (2008, p. 354) destaca o potencial educativo desses espaços, em que o ensino é baseado na representação material sendo capaz de dar concretude ao que antes era somente abstrato nas explanações em sala de aula.

Além dessa proposição, temos os depoimentos dos Entrevistados C e D que pedem "a produção de recursos didáticos", pois "isso torna o aluno partícipe do processo de compreensão e elaboração de maneiras de pensar a própria História, como algo próximo dele". Na fala do Entrevistado F deve-se usar "o cotidiano do aluno no bairro em que mora ou através de relatos sobre a cidade que eles conhecem". A entrevistada deste profissional remete ao que Bittencourt (2008, p. 168) argumenta sobre a História a partir do cotidiano, abordando o conteúdo regional próximo ao aluno.

Essa ideia, no entanto, é questionada pelo entrevistado D que defende ser mister o "trabalho com materiais adaptados dentro de sala de aula não só na disciplina de História quanto em outras". Na opinião desse entrevistado, esses materiais adaptados devem buscar a visualidade, podendo ser "adaptação de materiais confeccionados" já que não somente os "recursos eletrônicos contemplam a necessidade dos alunos". Além disso, a confecção de materiais é um exercício para o próprio professor que não ficará "refém da indústria cultural", tendo assim autonomia criativa (BITTENCOURT, 2008, p. 298).

Um outro ponto chave na inclusão do aluno na escola regular é a sala de AEE. No depoimento do entrevistado E, este é um espaço que tem "dado suporte nas 'atividades para casa' e nas atividades que não conseguiram finalizar em sala, uma vez que os alunos surdos não têm o apoio da família para fazê-las em casa". O AEE é uma das grandes marcas da escola inclusiva que trata de prestar um atendimento escolar, extraclasse e em contra turno, fornecido aos alunos público-alvo da educação especial (DAMÁZIO, 2007, p. 15). Segundo Damázio (2007), este atendimento, para alunos surdos, é dividido em "três Momentos Didático-Pedagógicos": o primeiro "Libras na Escola Comum", em que se trabalha os "conteúdos discutidos em sala de aula", neste momento, por exemplo, o professor de História repassa ao AEE o que está sendo discutido para que se possa fazer "adaptações, criações de sinais-termos e reforço do conteúdo em debate". O segundo momento é "o ensino de Libras", que propiciará ao aluno conhecimento gramatical de sua língua como "língua materna". No terceiro momento "o ensino da Língua Portuguesa", "na modalidade escrita", como forma secundária de idioma (DAMÁZIO, 2007, p. 25).

O AEE acaba tendo a missão de apoio extra aos alunos surdos, o que tem sido determinante na garantia de sucesso escolar do aluno surdo, como fica expresso na proposição levantada pelo Entrevistado B que amplia a missão da sala de AEE e defende um "diálogo para poder fazer um trabalho em conjunto", já que são três eixos de trabalho que têm influência direta na 
educação de surdos. Os Entrevistados C e D levantam uma questão importante que é a "preparação para lidar com as particularidades dos alunos surdos", tendo em vista "que em muitos casos, esses profissionais não possuem formação especializada para lidar com questões metodológicas".

Uma das premissas de AEE, defendida pelo Ministério da Educação, é que a Libras seja inclusa no planejamento, isso sendo feito pelo professor especializado do AEE juntamente aos professores de turma comum da disciplina respectiva, dos professores de Língua Portuguesa e de Libras (DAMÁZIO, 2007).

Ao questionar os entrevistados sobre o nível de satisfação com a inclusão de alunos surdos nas salas regulares de ensino obtivemos como respostas positivas a dos Entrevistados A e C, que evidenciam este processo como "uma grande conquista, o convívio com as diferenças". Ao mesmo tempo, o Entrevistado $\mathrm{C}$ critica a pouca percepção de conteúdo, já que "em relação à aprendizagem, ainda é uma lástima". O Entrevistado F é o mais descontente com a situação inclusiva dos alunos destacando que "o aluno surdo não tem acessibilidade, favorecido principalmente pela falta de compromisso de muitos profissionais que apesar de terem formação não tem responsabilidade com o processo de ensino e aprendizagem do surdo". O Entrevistado D define a "inclusão como ponte para e interação social", salientando que essa questão "perpassa a educação básica". O Entrevistado B evidencia o problema, chamando-o de "fracasso escolar", por conta do fato que as "escolas de ensino regular não estão preparadas tanto em sua estrutura quanto na formação dos profissionais que atuam nas mesmas".

Aliado a essas proposições, Witkoski (2012 p. 33-34) indaga que "sequer professores com proficiência na língua de sinais" são garantidos aos alunos, fazendo com que o "professor ignorante na Libras" ainda assuma encargos relacionados ao ensino de língua portuguesa ou Libras para crianças surdas, ignorando o fato deste não ser proficiente em língua de sinais. Nas palavras da autora, ninguém se disporia a dar aula, por exemplo, de francês ou língua portuguesa aos alunos franceses se esse docente não fosse proficiente nesses dois idiomas, contudo muitos querem, sem formação e aptidão, fazer da Libras uma profissão formal sem sequer ter uma intimidade com essa língua.

São vários os relatos de satisfação ou insatisfação quanto à inclusão dos alunos surdos. Apesar dos problemas, a visão do Entrevistado E é que este processo é "válido e positivo, frente ao passado limitado no qual os surdos viviam, ou seja, o oralismo". Em comum, todos os entrevistados concordam que há muito a avançar e que a proposta bilíngue está em processo de consolidação nas escolas. Em virtude disso, questionamos quais as maiores dificuldades que existem para a inclusão dos alunos surdos no ensino de História. Conforme o entrevistado A afirma, a dificuldade quanto à oralidade e à escrita está presente de forma acentuada na "compreensão dos textos, principalmente a questão da subjetividade". Os Entrevistados B e F corroboram com esta ideia e pontuam que essa dificuldade também existe em "localizar os conteúdos no tempo/espaço", ou seja, relacionar os conteúdos estudados. Para o Entrevistado C, a principal causa dessas dificuldades é a própria postura docente em privilegiar 
demasiadamente a oralidade no "uso exacerbado da fala". Para contornar isso, esse entrevistado aponta "que poderíamos usar mais as imagens em sala de aula, como uma forma de apresentar de maneira visual as questões e temporalidades da História". Segundo o Entrevistado D, que ratifica essas falas, são necessárias revisões no uso da "oralidade" para a máxima utilização de "recursos visuais".

Witkoski (2012, p. 46-47) trabalha com o conceito de bimodalismo aludindo às práticas pedagógicas que "hierarquizam" a língua portuguesa como base instrucional para surdos. Esse fenômeno está presente em escolas regulares inclusivas, escolas especiais e escolas "ditas bilíngues" e, ainda, perpetua-se na educação dos surdos porque ainda vemos essa hierarquização sendo trabalhada nos currículos da educação básica com extrema naturalidade. Sacks (1998) apresenta uma premissa sobre mudança histórica que permite grande reflexão, para ele "não são (geralmente) as ideias dos filósofos que mudam a realidade, e tampouco, inversamente, a prática das pessoas comuns. O que muda a história, o que desencadeia as revoluções, é o encontro dessas duas coisas" (SACKS, 1998, p. 29). E a partir dessa ideia percebemos que muitas têm sido as dificuldades para relacionar reflexões teóricas com práticas voltadas à comunidade surda para que produzam de fato melhorias significativas no processo de ensino e aprendizagem.

É válido salientar que há ainda pouco uso da TDIC "que podem mediar facilmente a interpretação a distância da língua de sinais contribuindo para a formação, o acesso à informação e a difusão da cultura para surdos" (CORRÊA; CRUZ, 2019, p. 39). Já que a ausência de recursos humanos se apresenta como um antigo empecilho a ser resolvido, pensar em recursos digitais poderia minimizar os impactos dos prejuízos que os surdos recebem em sua educação. Portanto, recorrer aos recursos humanos, destacando o TILS, aos recursos digitais, destacando a TDIC, é necessário, pois a partir dessa perspectiva são viabilizadas formas diferenciadas de comunicação, conforme preconiza a política nacional de educação especial na perspectiva da educação inclusiva.

A TDIC é muito discutida dentro da BNCC (2017) e essas questões debatidas são compiladas no DCEP (2019) nos conteúdos, conhecimentos, competências e habilidades. Esses dois documentos educacionais firmam-se essencialmente na telemática. Prega-se nesses documentos que nas diferentes áreas, permitam aos estudantes apropriarem-se das "linguagens da cultura digital, dos novos letramentos e dos multiletramentos", ressaltando que essa apropriação sirva tanto para "explorar" quanto a se "produzir". Com relação ao plano de método, há explícita solicitação de que os conteúdos sejam trabalhados para que os planos de conteúdo sejam coerentes com as capacidades que se pretendem. Corrêa e Cruz (2019, p. 44) indagam que, "no âmbito escolar, incluir significa reunir esforços com o objetivo de atender a todos, para isso é necessário muitas vezes reconsiderar e reestruturar currículos e dispor de recursos para que todos tenha igualdade de oportunidade".

Então, temos de pensar em educação de surdos além da sala de aulas, pensar sobre como se dá a nossa relação de produção e consumo das informações disponíveis à comunidade surda. Além 
disso, aos que são bilíngues, lembrar da necessidade de participar do universo digital inclusivo, atuando como produtor destes conteúdos voltados à comunidade surda. Todo ideal da telemática é visto nesta competência como forma de linguagem humana, tal qual se valoriza a linguagem "visual-motora", como a "Libras, a escrita, a corporeidade, o visual" dentre outras formas (BRASIL, 2017, p. 09). Ao solicitar a intervenção da TDIC no plano curricular, a base nacional e o currículo estadual iniciam um discurso que pede que estes instrumentos também estejam dentro da abordagem escolar e dentro das proposições de método e técnica do docente (BRASIL, 2017, p. 16 e 17).

A cultura digital, crescente no mundo globalizado, foi marcada por alguns tabus. Por exemplo, por muito tempo perdurou a ideia de que a telemática geraria a substituição do trabalho humano. $\mathrm{Na}$ prática, ela tem gerado uma reconfiguração das formas de trabalho, ou seja, "a classe trabalhadora não é idêntica àquela existente em meados do século passado, ela também não está em vias de desaparição, nem ontologicamente perdeu seu sentido estruturante" (ANTUNES; ALVES, 2004, p. 336). Ao patrocinarmos uma reconfiguração dos esforços pautados na produção digital estendemos as possibilidades de armazenamento de informação e agregamos um método a mais a ser praticado na condição de ser docente.

As pesquisas relacionadas à identidade, cultura, educação e poder têm demonstrado a necessidade de se apresentar mais as produções surdas, a visualidade e a linguística como norteadores na escolarização desses sujeitos. Parte-se, nessa perspectiva, da premissa dos estudos culturais do sujeito surdo para construção curricular desses indivíduos. Neste debate acreditamos que "em primeiro lugar, os Estudos Culturais permitem-nos conceder o currículo como um campo de luta em torno da significação e da identidade", sendo essa educação significativa que buscamos explorar nesta pesquisa. Percebemos que "a partir dos Estudos Culturais, podemos ver o conhecimento e o currículo como campos culturais, como campo sujeitos à disputa e à interpretação, nos quais os diferentes grupos tentam estabelecem sua hegemonia" (SILVA, 2009, p. 134-135).

Sabemos que há necessidade da TDIC ao mesmo tempo que conhecemos as limitações ainda oferecidas pelo sistema público de educação no Brasil. Witkoski (2012 p. 94) dialoga com esse questionamento sobre a necessidade de harmonia entre métodos inovadores e tradicionais indagando que "a visão simplista é desqualificada em relação aos recursos visuais, tais como filmes e confecção de cartazes, demonstraram que o uso desses estava muito mais voltado ao preenchimento das horas do que para seu efeito de aprendizagem". Disso, podemos salientar que até mesmo recursos tão importantes aos alunos surdos podem ter efeito alienante não cumprindo com o objetivo de aprendizagem.

\section{CONSIDERAÇÕES FINAIS}

Com este artigo esperamos ter contribuído para o campo das publicações de textos acadêmicos sobre os usos das TDIC e da Libras. Além disso, buscamos debater questões para compreensão dos anseios de uma comunidade surda que ainda luta por espaço numa sociedade 


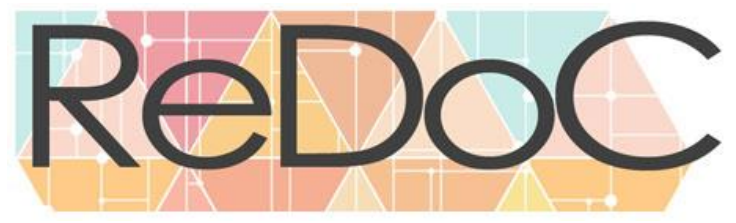

Revista Docência e Cibercultura

majoritariamente ouvinte e ouvintizada.

Este debate tem por finalidade problematizar a tradição escolar que privilegia a escrita como o único meio legítimo para o ensino e a aprendizagem. Neste movimento, apresentamos experiências sobre usos dos métodos digitais inclusivos na educação de surdos, notadamente, a Libras e a visualidade. Podemos concluir que não é produtiva uma visão simplista sobre as diversas metodologias. Portanto, deve-se atentar aos problemas trazidos pelo mundo tecnológico, ponderando que tais tecnologias não são exatamente "inimigas" e que os métodos tradicionais também possuem sua eficiência. Espera-se que os novos e os tradicionais métodos de ensino de História estejam igualmente dispostos aos processos de renovação curricular para o ensino de surdos.

Observamos nas entrevistas e nos documentos curriculares que a estrutura educacional tende a beneficiar as práticas oralistas e de escrita nas disciplinas de História e de Estudos amazônicos e, até mesmo, em toda a grade escolar. $\mathrm{O}$ uso dos recursos tecnológicos e materiais adaptados visualmente é uma das formas de sanar essa questão. Em trabalhos com essa perspectiva, o papel reflexivo do professor é a melhor forma de dar conta das novas demandas que a inclusão de alunos surdos apresenta nas novas configurações do currículo para a educação especial. Experiências de uso da cibercultura e no bilinguismo dão conta que elas podem empoderar a comunidade surda e provocar uma grande transformação em seu processo de inclusão social dando-lhes acesso, por exemplo, ao ensino superior.

\section{REFERÊNCIAS}

ANTUNES, Ricardo; ALVES, Giovanni. As mutações no mundo do trabalho na era da mundialização do capital. Educação \& Sociedade, v. 25, n. 87, p. 335-351, 2004.

BITTENCOURT, Circe Maria Fernandes. Ensino de História: Fundamentos e Métodos. São Paulo: Cortez, $2^{\circ}$ ed. 2008.

BRASIL. Lei De Diretrizes E Bases Da Educação Nacional: lei nº 9.394, de 20 de dezembro de 1996, que estabelece as diretrizes e bases da educação nacional. Disponível em < http://www.planalto.gov.br/ccivil_03/leis/19394.htm> Acesso em 21/06/19.

BRASIL. A Base Nacional Comum Curricular (2017). Ministério da Educação, Brasília, DF: MEC, 2018. Disponível em <http://basenacionalcomum.mec.gov.br/> acessado em $26 / 11 / 2019$.

CORRÊA, Ygor. CRUZ, Carina Rebello. (org.) Língua Brasileira de Sinais e Tecnologias Digitais. Porto Alegre: Penso. 2019. 
DAMÁZIO, Mirlene Ferreira Macedo. Atendimento educacional especializado. Ministério da Educação. Brasília. DF. 2007.

LINS, Heloisa Andreia de Matos. Experiências docentes ligadas à educação de surdos: aspectos de formação. Org. Campinas. SP. Leitura Crítica. 2012.

PARÁ, Documento curricular para educação infantil e ensino fundamental do estado do Pará. Belém, PA. 2019.

SACKS, Oliver W. Vendo vozes: uma viagem no mundo dos surdos. São Paulo. Companhia das Letras. 1998

SALLES, Heloísa Maria Moreira Lima. Ensino de língua portuguesa para surdos: caminhos para a prática pedagógica. Brasília: MEC, SEESP, 2004.

SILVA, Tomaz Tadeu da. Documentos de identidade: uma introdução às teorias do currículo. Belo Horizonte: Autêntica, 2009.

SKLIAR, Carlos. A surdez: um olhar sobre as diferenças. Editora Mediação. 5º edição, 2011.

STROBEL, Karin. As imagens do outro sobre a cultura surda. 2. ed. rev. Florianópolis: Ed. da UFSC, 2009.

WITKOSKI, Sílvia Andreis. Educação de surdos e preconceito.1. Ed. Curitiba, PR: CRV, 2012.

Este é um artigo de acesso aberto distribuído sob os termos da Licença Creative Commons Atribuição Não Comercial-Compartilha Igual (CC BY-NC- 4.0), que permite uso, distribuição e reprodução para fins não comerciais, com a citação dos autores e da fonte original e sob a mesma licença. 